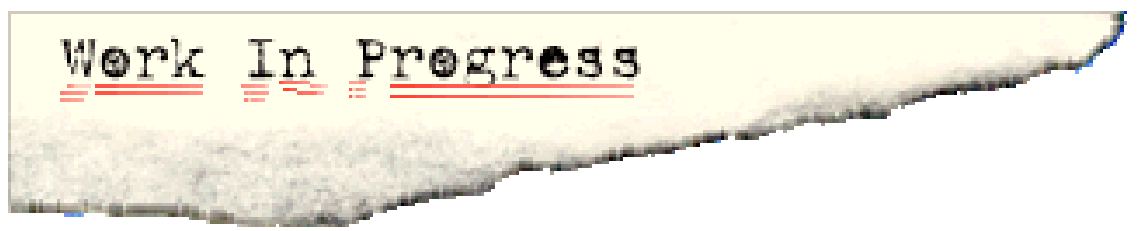

Accepted for publication by British Educational Research Journal
This article has been accepted for publication in British Educational Research Journal and the final (edited, revised and typeset) version will be published 2007, vol 33(1): 61-74 (C) British Educational Research Association

\title{
School violence, school differences and school discourses
}

\author{
Chris Watkins ${ }^{1}$, Melanie Mauthner ${ }^{2}$, Roger Hewitt ${ }^{3}$, Debbie Epstein ${ }^{4}$, Diana Leonard ${ }^{5}$ \\ Address for Correspondence: Chris Watkins, University of London Institute of Education, \\ 20 Bedford Way, London WC1H OAL UKＥmail: c.watkins@ioe.ac.uk
}

\section{Abstract}

This article highlights one strand of a study which investigated the concept of the violenceresilient school. In six inner-city secondary schools, data on violent incidents in school and violent crime in the neighbourhood were gathered, and compared with school practices to minimise violence, accessed through interviews. Some degree of association between the patterns of behaviour and school practices was found: schools with a wider range of wellconnected practices seemed to have less difficult behaviour. Interviews also showed that the different schools had different organisational discourses for construing school violence, its possible causes and the possible solutions. Differences in practices are best understood in connection with differences in these discourses. Some of the features of school discourses are outlined, including their range, their core metaphor and their silences. We suggest that organisational discourse is an important concept in explaining school effects and school differences, and that improvement attempts could have clearer regard to this concept.

\section{Background context and stance}

Some politicians, public commentators and some educators currently focus on a perceived increase in violence to the person within and around schools. The research project which is described in part here was one of the 17 studies in the ESRC Violence Research Programme. It set out to investigate whether schools differed in their approach to violence, especially in inner-city areas where levels of criminal violence in the neighbourhoods were apparently high. The term "violence-resilient school" was coined for a number of purposes, primarily to focus on the professional hunch of teachers, local advisers and members of the research team that there existed some schools with a low level of school-related violence in localities with high levels of violence.

The concept of resilience has developed in studies of individual development as a recognition that deterministic ideas of 'environment as cause' do not explain what is known about individual variation in development. So resilience refers to "successful adaptation despite challenging or threatening circumstances" (Masten et al, 1990). We sought to scale up this idea to examine the relations of organisations to their environment, and to

\footnotetext{
${ }^{1}$ University of London Institute of Education

2 Open University

${ }^{3}$ University of London Goldsmiths College

${ }^{4}$ Cardiff University

${ }^{5}$ University of London Institute of Education
} 
investigate comparable organisational successes despite environmental adversity. Resilient individuals - children - display social competence, problem-solving skills, autonomy, and a sense of purpose and future (Benard, 1993). We sought to investigate whether schools as organisations might be characterised as resilient, and if so whether they displayed any common characteristics. However the relation between organisation and environment was not cast as a defensive one, sometimes simplified into the idea that some schools were more effective than others in "keeping violence at bay", as though all "cause" was outside the walls. Rather we conceptualised the possibility that the school might play a role in both the management and manufacture of violence, so were also interested in the internal processes.

The research reported here, therefore, was a multiple case study of school differences, which aimed to uncover organisation-level processes and the detailed phenomena of school practices. Rather than adopt organisational concepts such as school culture which have sometimes been used in a unitary way to homogenise the school, we sought explanations which maintain the detail and diversity of organisations. This form of explanation has not appeared in earlier literature.

\section{The explanation of school differences in pupil behaviour}

The idea that different schools are associated with different patterns of difficult behaviour has become broadly accepted but remains poorly explained. Over three decades ago, a seminal study identified markedly different rates of delinquency among pupils attending different schools in the East End of London (Power et al, 1967), but these could not be attributed to differences in intake or neighbourhood. Most delinquent acts took place outside school, and the authors admitted "we have explained nothing" (page 543), redescribing the phenomenon as some schools protecting children from the risk of delinquency. Other studies suggested that schools did not make a single uniform difference, and that different schools were associated with different patterns. For example, Cannan (1970) suggested that even the style of delinquency and its age of onset varied across comparable schools: one was associated with more petty theft while in another pupils specialised in 'taking and driving away'. This was said to indicate that "the school may exert 'cultural' pressures on delinquency" (page 1004), but the processes through which this happened were not explained.

Studies of school differences in exclusion showed a similar picture. Large and consistent differences in the number of pupils excluded or suspended on disciplinary grounds from 37 secondary schools in Sheffield (Galloway et al, 1982), were again not attributable to any aspect of its catchment area or intake. No explanation was testable in the data, but the suggestion was made that aspects of "policy and practice" in schools were worthy of intensive study (page 32).

School differences in truancy, delinquency and attainment across nine secondary schools with similar intakes in one area of South Wales, were found to remain consistent over some years (Reynolds and Murgatroyd 1977a, 1977b). Explanations offered by these authors ranged from a "problem-prone-intake of children" (Reynolds et al 1976) to "a disaffectionprone school" (Reynolds 1984). On other occasions the key was seen as the school strategies, which were said to vary between "incorporation" and "custodial" (Reynolds et al, 1980) and "coercion" (Reynolds and Sullivan, 1981). However little evidence is given of the phenomena on which these explanatory constructs were founded.

A study of school differences, by now coming to be called "school effectiveness", showed significant differences between twelve London schools on a composite measure of a range of pupil behaviours (Rutter at al., 1979). The scores on this measure for some schools were five times greater than for other schools. Various "school processes" were found to have a combined effect, both on behaviour scores and other "outcomes", so the authors concluded "we have suggested that some kind of overall school 'ethos' might be involved" (page 182). 
However, available measures of ethos or climate had been rejected in the initial design, and the work contains no conceptualising of school-level influences to explain the differences.

Further explanations of differences in school behaviour may be found in studies from USA. Metz (1986) found that in those High schools where teachers co-operated with one another, inter-racial harmony and co-operation among students was better. Bryk and Driscoll (1988) identified the features of a communal form of school organisation and went on to show how schools vary in this. Their study of 340 secondary schools in Chicago (Bryk, Lee and Smith, 1990) showed that better behaviour was associated with schools that develop collegial relations among adults and which bring teachers into frequent contact with other staff and with students in settings other than the classroom. Here again large-scale concepts such as communal form of organisation or ethos might be invoked, without being explained in the smaller-scale processes which make up the daily practice of the organisation.

School differences have occasionally been linked to the different explanations used in a school. Predominant explanations for difficult behaviour vary from school to school: some specialise in family background attributions, others in folk theories regarding age, and others still in talk of "difficult neighbourhoods" (Watkins and Wagner, 2000). The suggestion is that the explanations a school offers relate to the patterns of behaviour. Those schools which see themselves as part of the picture in patterns of difficulty believe the problem of disruptive behaviour is within their power to resolve: they have smaller use of exclusion (Maxwell, 1987). Schools also vary in their ways of telling stories of difficulty. Teachers in schools characterised by collaboration seek help widely to solve problems and increasingly come to believe that student learning is possible with even the most difficult students: in other schools, teachers may swap stories about a child's errant behaviour, focus on behaviour as though disconnected from learning and see punishment as the solution to problems (Rosenholtz, 1989). The former schools are more successful: they do not blame, either pupils, their families, or themselves, but they actively seek solutions. Senge (1990) identifies a general tendency in organisations to say "the enemy is out there". It happens most in a climate of blame. Individualised ("inside the person") and externalising ("outside the walls") explanations may be common in schools overall, but some organisations, and some schools, may employ them more than others. Such explanations can carry negative effects: by removing their contribution from the picture, teachers can feel worse and things can get worse; by diverting the reasoning for difficulties away from the school, they may reduce their power to improve the state of affairs.

When teachers discuss the means of improving difficult behaviour, they place themselves more centrally in the picture than when discussing "causes" or "origins". Miller (1995) showed that although 24 teachers attributed responsibility for the origins of difficult behaviour to parents and pupils, they attributed responsibility for improvement to themselves. The balance between talk about improvement and talk about cause may be a crucial element in a school's profile of action, and there is a possibility that the balance may vary from school to school.

\section{The research: methodology}

For the overall study, thirteen inner-city state secondary schools were contacted to seek their expressions of interest: ten replied. AfAfter funding had been granted, we discussed eight of the schools, which clustered in two local areas, with local advisers for those areas, seeking their view on whether these schools were differently successful in matters of school violence. Six schools which were impressionistically seen to be differing in their approaches were recruited. Four were co-educational, two were single sex - one for boys, one for girls.

For each school, the pattern of school-related violent incidents was obtained through examination and selection of exclusion records for two successive school years, and tabulating exclusions which were violence-related (physical and verbal) and for more than three days. This was seen as the best evidence base available on violent incidents, 
notwithstanding our view that any such records are socially constructed accounts with specific purposes. Matters of school policy (such as the decision to exclude or to avoid exclusion for a wide range of reasons) must be partly reflected in such data. Nevertheless we took these particular records to reflect the levels of violence in each school, since it was the sub-set of exclusions which recorded reports of violence, as opposed to pupil misbehaviour more widely. Had our focus been wider misbehaviour we would not have assumed that this was adequately reflected in exclusion data. The study of 86 schools by Hart et al (1995) challenged this common assumption, and concluded "These findings strongly suggest that student suspension rates should not be used to indicate the degree of misbehaviour in schools". In their data, overall exclusion rates indicated more about the school's discipline policy and the self-esteem of teachers.

For our measure of neighbourhood violence, the Police Performance Information Bureau provided data on reported violent crimes (violence against the person plus rape) for one year tabulated by grid reference. For each school the total number of crimes was calculated for a square reaching $1 \mathrm{~km}$. in all directions from the school. This area seemed appropriate since all six schools had pupil intakes controlled by LEA procedures, and their "catchment area" was predominantly the local neighbourhood (in contrast to those urban schools where selected pupils travel from a wide area). In the case of one school which had become popular in its local area, it was said that its catchment had become smaller than a $1 \mathrm{~km}$. square.

School organisational practices in responding to violent incidents and in preventing violence were elicited through interviews with a range of staff and pupils. A "family sample" of staff across the organisation typically included head teacher, senior managers, middle managers, main-scale teachers and staff with particular roles in relation to pupil behaviour. On average eight staff interviews of up to an hour in length were conducted in each school. The interview frame addressed two major areas: the management practices in relation to violence, and the degree of connectedness among people in the school and in the local community. This focus reflects our interest in the school itself and its internal and external social relationships. Thus the interview frame raised the following themes:

1. Picture of the school generally: stable or disrupted

Culture (including the Management culture)

2 . The school's broad approach to the area of violence

3 . How the school responds to any incidents of violence which might occur.

4. Practices which set out to prevent incidents of violence

5. Practices for monitoring incidence of violence and analysing any patterns

6. Particular practices or focus on racist, sexist \& homophobic violence

Communal Organisation

7. Practices which promote connections within school:

a. pupil-pupil relations across the school

b. teacher-pupil relations outside the classroom

c. teacher-teacher relations

Community Links

8. The way that the school connects with its community:

a. school-parent links

b. school-neighbourhood

Curriculum

9. Tailoring any part of the curriculum to the prevention of violence

\section{Differences in the quantitative data}

Levels of neighbourhood violent crimes were not simply reflected in the levels of in-school violence. Some schools in neighbourhoods marked by high levels of violent crime show 
evidence of as little in-school violence as those in areas with substantially lower levels of neighbourhood crime.

\begin{tabular}{|c|c|c|}
\hline School & $\begin{array}{c}\text { Exclusions for violence } \\
\text { per 1000 pupils } \\
\text { (average over two years) }\end{array}$ & $\begin{array}{c}\text { No. of violent crimes in } \\
\text { 1km square around school } \\
\text { (one year) }\end{array}$ \\
\hline A & 59 & 497 \\
\hline B & 23 & 575 \\
\hline C & 48 & 1534 \\
\hline D & 40 & 515 \\
\hline F & 86 & 624 \\
\hline G & 37 & 270 \\
\hline
\end{tabular}

Table 1: School exclusion for violence and incidence of violent crime in neighbourhood, by school

This data lent support to the idea of a school effect, especially the institutional effect of single-sex schools (School B all girls, School F all boys). Within the four coeducational schools the data supported the idea of a differential school effect, School G, in an area of comparatively low neighbourhood violence has relatively high school violence, whereas School C in an area of relatively high neighbourhood violence has relatively low school violence. Given these indications of school differences in effects, we turned to examine organisational practices through the interview data.

\section{Identifying school practices}

Interview transcripts were first analysed along the lines of the interview schedule. This data was compressed to achieve a composite view of the school's practices. At the final stage of this compression a brief vignette was written by two members of the team. Examples follow from the two schools mentioned above.

\section{School C Practices}

Staff describe first responses to violent incidents as including the gathering of evidence from all concerned and utilising it "Rather than dealing with it on an impulse".

Exclusion is not automatic, "the situation is assessed and a decision is then taken". Pupil-teacher relations are referred as both prevention and response: "tutors are aware of children that are feeling anxious or whose circumstances are not positive". "as a response teachers/tutors might well spend time talking to those individuals". Other staff are mentioned: "learning assistants talk through what's happened at the end of a day".

Staff training is mentioned, as is monitoring and review: "records of the patterns of behaviour are filtered down towards the year team meetings where tutors find out what the patterns are. These are then addressed".

Pupil-pupil relations are supported and utilised "Usually our other students are good at intervening. Students off their own bat will quite often try to reason the student out of it". Upper school students were trained to mentor the younger students. A need for conciliation after exclusion is highlighted "It's powerful to have the parties spend a few minutes talking. Put it in the past".

Community connections include a parents forum, a playground helper scheme for past students, and youth club provision at dinner-times.

Community links are handled proactively: if there are inklings of difficulty between neighbourhood groups, the head or others will liaise with parents, youth workers, community groups, and police.

Preventive provision mentioned includes curricular provision such as PSHE. Curricular constraints are cited as leading to less attention than teachers would like in English and Humanities. There is a nurture group for Year 7/8, a GEST project which runs small groups, special groups for boys and for girls from particular community groups, a refugee boys group. Special assemblies and focus weeks are used. 
School G Practices.

The predominant practices in relation to incidents of violence are the school's "ways of dealing with it", including assertive discipline, taking statements, sanctions, exclusions, sending home, contacting parents, police. "anything that is quite deliberate and planned then we would automatically get the parents and involve the police". Some staff describe "standard pathways for such incidents, whereas others say "it isn't really clear what the procedure is". Various roles in the school hierarchy are engaged to "deal" with incidents: "sometimes everybody has to be involved from the class teacher to the form tutor to the Head of House and then the parents", but again another says "I think there is a lack of consistency about who you report it to". When asked about monitoring, staff report that "staff are meant to record verbal and physical abuse in an incident book". Additional or specially qualified staff are a major feature: youth workers attached to the school, attendance workers, counsellors, community police. They organise clubs and activities before school, at lunch-time and after school, and some work is specific: "input from a youth worker for anger management". One-off curriculum contributions are described "I have to deliver a lesson to every tutor group on anti-bullying" but without a coordinated approach "we haven't got it mapped out on the curriculum". Pupil-pupil relations are related to the house system "It's making pupils mix with pupils from other years, at lunch times and break times", and to a committee of older students acting as anti-bullying counsellors. Teacher-pupil relations outside the classroom are occasionally mentioned: "We eat with the children as well - their behaviour is excellent in those areas". Teacher-teacher relations are not a focus for practice: "there's a staff sports activity on a Friday", but "we're notorious for staying in our rooms, and hardly every coming out".

The school is used as a site for many activities, apparently for school-age children. School-parent relations include disappointing attendance at parents' evenings, and "Unfortunately the PTA..... that died out".

\section{Differences in school practices}

The picture which emerged was not one of simple or single practices making the difference. Instead the degree of connectedness in the organisation and in its practices emerged as the dimension of difference (Hewitt et al, 2002). Of particular significance are:

- The range of policies and practices for dealing with violence and its potential emergence.

- The quality and extent of communications within schools over violent incidents, especially staff-student communications.

- The quality of relationships within schools - between staff and between staff and students.

- The engagement with and relationship to the neighbourhood of the school and its communities of interest.

So School C above had a wider range of proactive strategies for developing pupils skills, spent considerable time reviewing and learning from incidents, and was proactive in community relations. School $\mathrm{G}$ had a more limited range of strategies which were reactive in nature, less focus on interpersonal relations within school, and a more circumscribed view of relations with the community.

These difference give support to the idea that schools as organisations could be more or less resilient. Even within challenging environments, schools can be successful through:

- a high focus on communication and social relations

- a purposeful and proactive stance towards potential difficulty

- a focus on their own role in creating solutions 


\section{The emergence of school discourses}

A focus solely on practices could portray schools as mechanical systems with interchangeable practices designed for maximum efficiency. But in human systems practices reflect the meanings which participants hold for them. In our interviews a further difference between schools emerged: the ways of talking about violence, its causes, locations, and what needed to be done about it, seemed to vary across the schools. This directed attention from practices to discourses.

A discourse is "a system of statements which constructs an object" (Parker, 1992:5): thus violence may be seen as differently constructed in different schools. Further, "A discourse refers to a set of meanings, metaphors, representations, images, stories and so on that in some way produce a particular version of events" (Burr, 1995: 48). While recognising that it can only be an individual who offers a narrative, it is also possible to identify wider patterns in their content and style. Pearce and Cronen (1980) take the view that narratives and communications offered by an individual can be analysed at various levels: individual, family, organisation, culture. Thus it is meaningful to "read" one or more narratives for the discourse of the context. Teachers' interview transcripts can be analysed for individual, role and organisational discourses.

Concepts of narrative in organisations and of organisational discourse have attracted increasing attention (Czarniawska-Joerges, 1996, 1997; Grant et al 2001). However between-organisation differences have not yet been fully explored, and such literature has not researched schools. The stance could offer a way of examining the accounts which schools give for: (a) the explanations of difficult behaviour, and (b) the interventions they consider it meaningful to make. In this sense it provides a richer view of organisational culture by viewing culture as "the ensemble of stories we tell ourselves about ourselves" (Geertz, 1973).

Discourses regarding violence have been examined (O'Connor 1995a), but not yet at the organisational level. At the individual level, O'Connor (1995b) analyses individual discourses in terms of personal agency, At the role level, Auburn et al. (1995) explored how police and suspects make and manage accusations of violent involvement. At a wider societal level Berns (1999) demonstrates that discourses of violence in popular women's magazines continue to portray domestic violence as a private problem and most often the victim's problem. Phillips and Henderson (1999) analysed professional and popular literature describing male violence against women, noting a silence regarding men as perpetrators and the visibility of women in such literature. The phrase "male violence" was rarely used and the male gender was infrequently mentioned, whereas female gender was often present in the identification of victims.

In this light a second content analysis of the data was undertaken. Transcripts were revisited and the unit of analysis was any statement which could be seen as a description, explanation, or solution for violent behaviour. These were extracted and listed in two broad categories: those which identify and explain violence (the "production of difficulties" discourse), and those which give meaning to proposed solutions to violence (the "solution of difficulties" discourse). These statements were then grouped into emergent categories. Analyses were completed separately for each school so that diversity between schools was honoured. Again the final stage of this compression was a brief vignette. Examples from the same two schools follow. 
Staff talk about a wide range of aspects in explaining violent incidents: the school environment, time patterns in the school day, teacher presence, accidental violence, particular spaces, the developmental needs of year groups, inter-group dynamics including dimensions of gender, race and sexual orientation. Mention is made of pupils' anger-management skills, their language capacities, and social skills for handling accusations.

They also include dynamics in the neighbourhood, the school in its local environment, youth club events, Just one teacher says "sometime it's linked to problems on the estate", while another says "We now find that the real violence happens in the community: people come in and tell us that there's been a fight in this and that youth club but it doesn't impinge now on the school".

Responses and preventive work are mentioned regularly: "why wait for the big bang?". The teachers talk in a way which places them in a key role for preventing difficulty: "if you know how to put it across to the students and develop a good relationship the behaviour is going to be minimal".

The act of listening is mentioned regularly: "there is an ethos in this school that teachers care about kids and that if they were to go completely out of control and even become violent, they would still be listened to; they won't be just purely dealt with through the code of conduct". The concept of safety is mentioned as playing a key role in "I think we have been successful in making the school safe".

The multiplicity and connectedness of solutions is explicit: "lots of things make it a community feel, everybody's together", and the linkage between the problems they identify and the solutions they discuss is high.

School G-discourses

Staff speak of the causes of violence mainly in terms of the local area, the "community" and its "culture". A range of deficit adjectives are used to describe families and "difficult family backgrounds". Mentions are made of violent, aggressive and threatening parents. Yet in relation to this hypothesised home behaviour, school behaviour is described in different ways, ranging from "a release from home" to "bringing it in from home". Many mentions of difficult incidents are couched in terms of features of the pupils: problem children, difficult children, who "tend to solve their problems by being aggressive". "With a lot of violence that I come across it is people getting their retaliation in first." Pupils are described as being willing spectators of fights.

There is much talk which relates the causes of violence to the intake of the school, a rise in casual admissions to the school, pupils who have been excluded from other schools, from out of the area. In this context, school is talked about as an organisation under pressure, from inspection, from local authority policies on exclusions and admissions, National Curriculum constraints, and so on: "we have ten key issues and beyond National Curriculum we won't be looking”.

Special provision is deemed to be the answer: "schools need to have the classes and the specialists and the level of funding to be able to isolate those children". But the limits of this approach are also voiced: "we have some units but they are always full". Mentions of school culture and the school as a community are few, but school reputation is a concern: "your whole reputation for fairness actually depends on you being consistent". There are many mentions of staff as stressed, overloaded and feeling unsupported: illness and high turnover result. "if they have supply who don't know them it causes disruption" "the staff have almost completely changed when we went into special measures" 


\section{Discussion and Conclusion}

Comparing the school discourses identified in the six schools, we notice the following variations:

- some discourses have a greater degree of connection between the creation of difficulties and the solution to difficulties. In the most connected cases action clearly reflected analysis, and the degree of sophistication was evident. School C is an example where placing the school as one of a web of causes is associated with more schoolinitiated interventions. In the least connected cases, the school's action did not relate to the particular circumstances of a problem - it had become routinised. School G's struggle for set ways of dealing with incidents was not connected to its own explanations of the difficulties as produced outside the school.

- some discourses have a narrow range and seem oriented toward blame (or, equally, defence against blame). School G's talk of "problem pupils" is associated with procedures and specialist provision for such problems. This parallels the discourse of the supra-system which is strongly reactive, including in the policy advice which Government sends to schools. Other schools remain proactive and scan the problem more widely, and some studies suggest that these schools are associated with less difficulty (Rustique-Forrester, 2003).

- discourses display different underlying models of how the school as an organisation is to be described and understood. Some schools represent their organisation as a machine, others more as a community. Our findings on violence may support the view from wider studies: "these findings say something crucial about the way schools are organised: a personal-communal model is more effective than a rational-bureaucratic model" (Lee, Bryk and Smith, 1993).

- some school discourses on violence are notable for their silences. An example is that of homophobic violence (Epstein et al 2003). In some schools there was no mention of this dimension. On matters of "race" and gender, some of the schools were silent whereas other schools were not, despite experiencing frustration at the difficulty of addressing these dimensions in a policy environment which was itself often silent over them.

Overall our reading of the data suggests that the organisational discourse is strongly associated with the organisational practices. Schools which position themselves as outside the complex of causes may have a narrower range of practices. Those which cast themselves as depending on routinised responses may spend less time on communication. And those which talk about their relation with their environment in an embattled way may have less proactive a role in relation to their community - that is, less resilience.

The approach of considering school practices in association with school discourses offers richer insight into the way schools differ, and presents the following advantages:

- action and meaning are reunited, rather than their common separation in the instrumental talk of "what works" in schooling, a separation which has over-simplified the "transfer of good practice" (Fielding et al, 2005)

- the school is not assumed to be an organisation of homogeneous practices: the gathering of multiple voices in the organisation can highlight coherence or fragmentation, or conflict or resistance.

- new possibilities emerge in the field of improving school behaviour. Alongside a focus on school practices it is meaningful to explicitly address the discourse in a school. Kenway and Fitzclarence (1997) have begun to explore the possibility of a narrative approach to school violence, which includes work with perpetrators to build positive counter-narratives. Development work by Quong and Walker (2000) indicates that such work can be successful in school approaches to addressing bullying.

In conclusion, the school differences identified in this research are not adequately explained by recourse to school practices alone. The different constructions of violence in 
different schools not only inform the practices but are also phenomena in their own right, and provide additional foci for improvement attempts. The violence-resilient school not only acts in identifiable ways, it also 'talks' in identifiable ways.

Note

The research reported here was supported by ESRC award L133251041.

\section{References}

Auburn, T., Drake, S. and Willig, C. (1995) You punched him, didn't you - versions of violence in accusatory interviews, Discourse \& Society, 6, 353-386.

Benard, B. (1993) Fostering resiliency in kids, Educational Leadership, 51, 3, 44-48.

Berns, N. (1999) "My problem and how I solved it": Domestic violence in women's magazines, Sociological Quarterly, 40, 85-108.

Bryk, A. S. and Driscoll, M. E. (1988) An empirical investigation of the school as a community (Chicago IL, University of Chicago School of Education).

Bryk, A. S., Lee, V. E. and Smith, J. B. (1990) High school organization and its effects on teachers and students: An interpretative summary of the research, in: Clune, W. H. \& Witte, J. F. (Eds) Choice and control in American education (Philadelphia, Falmer Press).

Burr, V. (1995) An introduction to social constructionism (London, Routledge).

Cannan, C. (1970) Schools for delinquency, New Society, 16, 427, 1004.

Czarniawska-Joerges, B. (1996) Narrating the organization: Dramas of institutional identity (Chicago, University of Chicago Press).

Czarniawska-Joerges, B. (1997) A narrative approach to organization studies (Thousand Oaks, Sage).

Epstein, D., Hewitt, H., Leonard, D., Mauthner, M. and Watkins, C. (2003) Avoiding the issue: Homophobia, school policies and identities in secondary schools, in: Vincent, C. (Eds) Social justice and identity in education (London, Routledge Falmer).

Fielding, M., Bragg, S., Craig, J., Cunningham, I., Eraut, M., Gillinson, S., Horne, M., Robinson, C. and Thorp, J. (2005) Factors influencing the transfer of good practice: DfES research report RR615. (London, DfES/ University of Sussex \& Demos).

Galloway, D., Ball, T., Blomfield, D. and Seyed, R. (1982) Schools and disruptive pupils (London, Longman).

Geertz, C. (1973) The interpretation of cultures: Selected essays (New York, Basic Books).

Hart, P. M., Wearing, A. J. and Conn, M. (1995) Conventional wisdom is a poor predictor of the relationship between discipline policy, student misbehavior and teacher stress, British Journal of Educational Psychology, 65, 27-48.

Hewitt, R., Epstein, D., Leonard, D., Mauthner, M. and Watkins, C. (2002) The violenceresilient school: A comparative study of schools and their environments. (ESRC Violence Research Programme: Research Findings). Available online at:

http: / / www 1.rhbnc.ac.uk/sociopolitical-science/vrp/Findings/rfhewitt.PDF (accessed 14 February 2005)

Kenway, J. and Fitzclarence, L. (1997) Masculinity, violence and schooling: Challenging "poisonous pedagogies", Gender and Education, 9, 117-133.

Lee, V. E., Bryk, A. S. and Smith, J. B. (1993) The organization of effective secondary schools, Review of Research in Education, 19, 171-267.

Masten, A. S., Best, K. M. and Garmezy, N. (1990) Resilience and development: Contributions from the study of children who overcome adversity, Development and Psychopathology, 2, 425-444. 
Maxwell, W. S. (1987) Teachers' attitudes towards disruptive behaviour in secondary schools, Educational Review, 39, 203-216.

Metz, M. H. (1986) Different by design: The context and character of three magnet schools (New York, Routledge \& Kegan Paul).

Miller, A. (1995) Teachers' attributions of causality, control and responsibility in respect of difficult pupil behaviour and its successful management, Educational Psychology, 15, 457471 .

O'Connor, P. (1995) Speaking of crime - I don't know what made me do it, Discourse \& Society, 6, 429-456.

O’Connor, P. E. (1995) Discourse of violence (editorial review), Discourse \& Society, 6, 309318.

Parker, I. (1992) Discourse dynamics: Critical analysis for social and individual psychology (London, Routledge).

Pearce, W. B. and Cronen, V. E. (1980) Communication, action and meaning: The creation of social realities (New York, Praeger).

Phillips, D. and Henderson, D. (1999) "Patient was hit in the face by a fist..." a discourse analysis of male violence against women, American Journal of Orthopsychiatry, 69, 116 121.

Power, M. J., Alderson, M. R., Phillipson, C. M., Schoenberg, E. and Morris, J. M. (1967) Delinquent schools, New Society, 10, 19 Oct 1967, 542-3.

Quong, T. and Walker, A. (2000) Using stories to shift attitudes: The case of bullying, International Electronic Journal for Leadership in Learning, 4, 4, Available online at: http: / /www.ucalgary.ca/ iejll (accessed 14 February 2005).

Reynolds, D. (1984) The school for vandals: A sociological portrait of a disaffection-prone school, in: Frude, N. \& Gault, H. (Eds) Disruptive behaviour in schools (Chichester, John Wiley).

Reynolds, D., Jones, D. and St Leger, S. (1976) Schools do make a difference, New Society, July 29, 223-225.

Reynolds, D., Jones, D., St Leger, S. and Murgatroyd, S. (1980) School factors and truancy, in: Hersov, L. \& Berg, I. (Eds) Out of school: Modern perspectives on truancy and school refusal (London, John Wiley).

Reynolds, D. and Murgatroyd, S. (1977) Towards a socio-psychological view of truancy, in: Kahan, B. (Eds) Working together for children and their families (London, HMSO).

Reynolds, D. and Sullivan, M. (1981) The effects of school: A radical faith revisited, in: Gillham, B. (Eds) Problem behaviour in secondary schools (London, Croom Helm).

Rosenholtz, S. J. (1991) Teachers' workplace: The social organization of schools (New York, Teachers College Press).

Rustique-Forrester, E. (2003) Toward a contextual theory of school exclusion: A multi-layered view of the interaction between national policies and local school practices. PhD thesis (University of London)

Rutter, M., Maughan, B., Mortimore, P. and Ouston, J. (1979) Fifteen thousand hours: Secondary schools and their effects (London, Open Books).

Senge, P. M. (1990) The fifth discipline: The art and practice of the learning organisation (London, Century Business).

Watkins, C. and Wagner, P. (2000) Improving School Behaviour (London, Paul Chapman/Sage). 